\title{
A review on Flexible working Electrode of Dye Sensitized Solar cell
}

\author{
Qaisar Abbas*, Maham Sana, Zunaira yousaf, Qaiser Atta and Aqsa Hashmi \\ Department of Physics, COMSATS University Islamabad Lohore campus, Pakistan
}

*Corresponding author: Qaisar Abbas, Department of Physics, COMSATS University Islamabad, Lahore, Pakistan

\begin{abstract}
Due to extensive use of traditional energy resources environment pollution is very big problem now days. these resources are limited and are not environment friendly it is obvious from many researches that due to wide use of traditional energy resources the world would face many energy crises in next 50 years. So, the alternative resources are very necessary to overcome these types of the sever problems in the future. Dye sensitized solar cells (DSSCs) are best option for the utilization of renewable energy resources. Now a day's people are more interested in flexible technology of electronics like energy devices. In DSSCs electrodes are essential components for the working. To make the DSSC flexible electrodes should be adjustable on any surface. For the ease use of DSSC electrodes should be flexible because due to flexibility these can be installed on flat and curved surfaces. These flexible electrodes have no bad impact on environment and are also low cost and light weight. Flexible electrodes are very interesting in all type of the bendable electronic devices.
\end{abstract}

\section{Introduction}

Extreme use of petroleum derivatives has driven the world to move from the traditional power sources to a sustainable power source to meet the increasing demand for energy. Despite the fact that the procedure is progressive the capability of the sustainable power source has been all around discussed in the past decades. There are many energy resources like wind energy, but they are less efficient as compared to solar energy. Photovoltaic devices convert heat energy from the sun into electrical energy, these devices work on the principle of charge separation at the interface of two different materials which have different conduction methodology according to their properties. Silicon-based solar cells have been most important for this mechanism as they are considered as solidstate devices. The third generation of solar cell has been introduced that is dye-sensitized solar cell (DSSC). This technology has much importance for the conversion of solar energy into electrical energy [1]. Dye-sensitized solar cells (DSSCs) are getting impressive attention as contrasting to semiconductor-based thin film solar cells. Oregon and Gratzel in 1991 showed dye- sensitized solar cells (DSSC) are not expensive and can be used as an alternative to silicon solar cells [2]. The dye-sensitized solar cell is a semiconductor photovoltaic device which is used to convert solar energy into electrical energy [3].
This has been confirmed that the efficient work of Organ and Gratzel is the most cited article in the field of energy in the world [4]. According to the latest research, more than 17000 papers have been presented to fabricate the new material, characterization techniques for the launching of DSSC on large scale in the world [5]. During the past decades, the dye sensitized solar cell is considered one of the best photovoltaic devices for the conversion of solar energy into electrical energy. This is due to the uniqueness of the DSSC as its fabrication process is very simple, and materials required for construction are low cost and easily available. Moreover, the instruments used in the fabrication process are also less expensive and easily available. It has a high light to electricity transformation efficiency. Currently, it has archived sufficient efficiency to light up [6]. DSSC has fabricated on the conductive polymer which interestingly is lightweight, flexible, environmentally friendly and low cost. This unique manufacturing has led roll to roll function of dye-sensitized solar cell for the installation on curved and flat surfaces. However, the thermal instability of the polymer is still challenged for better efficiency. Polymer-based electrodes show less efficiency rate as compared to the DSSCs which have a glass substrate. However, many research groups have worked on the alternative of the polymer substrate to sustain the flexibility factor 
along with better conversion efficiency [7]. For the fabrication of flexible DSSC many techniques have been implemented such as Yamaguchi et.al introduced the compression technique for the purpose of constructing titanium dioxide $\left(\mathrm{TiO}_{2}\right)$ film on polymer substrate which onstitutes flexible properties with better efficiency. In this method, the particle size of $\mathrm{TiO}_{2}$ was large which showed a light confinement effect and the $7.4 \%$ conversion efficiency was achieved through this mechanism [8].

\section{History of Dye Sensitized Solar cell}

Dye sensitization was developed by silver halides chemistry which was for photography over a period ago. James Moser was the first who sensitized semiconductor with dye in 1887 during work of silver halides coated in erythrosine. In 1938 Gurney and Mott used dye-sensitized semiconductor crystal to transport electron from excited dye to semiconductor band. Maximum of the work, at the completion of the $20^{\text {th }}$ century, was finished on sensitizing low bandgap semiconductors for the determination of photography. Putzeiko and Trenin were the first who sensitized a wide-ranging bandgap material in 1949. They studied photoconductivity of Zinc Oxide powder sensitized with organic dyes [9]. There was a problem in early photo electrochemical cells that they contained a free dye in solution. Photons exited free dye, and dye moves back to a ground state very quickly without injection of an electron to the semiconductor. This problem was resolved by Osa et al. in 1976. He developed a monolayer of dye on semiconductor mutually bonded together with a covalent bond. Essential progress in DSSCs was the introduction of transition metal complexes as a sensitizer. In 1975 Gleria Memming used [Ru(bpy)3]+2, the first ruthenium (II) bipyridyl complex, in solution to sensitize $\mathrm{SnO}_{2}$. In 1980 Good enough et al. sensitized Ru(bpy) ${ }^{2}$ (dcbpy) on the surface of $\mathrm{SnO}_{2}, \mathrm{SrTiO}_{3}$, and $\mathrm{TiO}_{2}$. These cells attained $0.25 \%$ APE (absorbed a photon to current efficiency) and very smaller energy transformation efficiency yet. This low efficiency was because of the light absorption and slow reduction of oxidized dye. Grätzel et al. in 1988 used Polycrystalline $\mathrm{TiO}_{2}$ electrode having some specific roughness and sensitized with $\mathrm{Ru}$ (dcbpy) along with an aqueous $\left(\mathrm{I}^{-}-\mathrm{I}^{-}\right)$regenerative electrolyte and achieved 70\% IPCE. But the whole efficiency remained at $1 \%$. Following the previous work, In O’Regan and Grätzel $[4,10]$. It was understood that dye-sensitized solar cell is a feasible and environmentally friendly energy source. Many researchers worked on the improvement of efficiencies of DSSCs, as the efficiency is the most important factor of any working device, there are some recorded efficiencies the highest reported efficiency of Ru-based dye is $11.5 \%$ [11]. Recently researchers developed a very important DSSC by using Zn- based and Co-based dye which has the efficiency of $12 \%$ [12].

\section{Structure and Working of dye-sensitized Solar Cell Structure}

a) Components of dye-sensitized are enlisted below

b) Working electrode

c) Counter electrode

\section{d) Dye}

e) Electrolyte

\section{Working of DSSC}

DSSC has extraordinary different structure and properties as compared to other photovoltaic devices due to use of nanomaterial and molecular devices in it. A major component of DSSC is its working electrode also known as photoelectrode. The thin film of semiconductor material like $\mathrm{TiO}_{2}$ is deposited on the working electrode of DSSC then dye sensitizer is placed on it after that electrolyte is mixed on this system. Finally, the counter electrode is combined with the working electrode. The light falls on dye molecules these molecules absorb photon energy and attain excited state to the conduction band of semiconductor material thus electron from photoanode moves toward the external circuit and finally reaches at the counter electrode, here electrolyte performs its function of regeneration of dye molecules. The working electrode is made up of Transparent conducting glass (TCO). There Fluorine doped tin oxide glasses or Indium Tin oxide

glasses can be used for the purpose of working electrode [13].

\section{Transparent conducting oxides (TCO)}

Usually, TCO is an n-type semiconductor having a relatively high concentration of free electrons and wide band gap also have a high transmission rate of light and are electrically conductive. Examples of TCO is fluorine-doped tin oxide and indium doped tin oxide $[14,15]$. Fluorine-doped tin oxide (FTO) and indium tin oxide (ITO) are transparent oxides and can be coated on different materials like plastics, glass, and stain fewer steel materials. These oxides are thermally stable and have high charge mobility due to which they are able to enhance the optoelectronic properties of a material on which coating is required and these oxides are widely used in DSSC due to transparency and thermal stability $[16,17]$. With the increment of temperature ITO makes a bond with oxygen present in the environment that reduces the electrical conductivity of ITO [18]. In contrast with ITO indium-free FTO is more stable and can use hydrogen present in the environment. Glass based FTO are common in DSSC fabrication process [19]. FTO glass based DSSC is better than that of ITO glass based DSSCs [20]. 2 Flexible Electrodes for DSSC to reduce the weight and to add the flexibility in DSSC, polymer materials can be used instead of FTO. The transparent polymers are coated with Conducting Oxides. Polymers such as polyethylene naphthalene (PEN) and polyethylene terephthalate (PET) are being used to produce a flexible electrode for DSSC. For the installation of DSSC on different surfaces various shapes of electrodes were made. The problem with the flexible material is that they are thermally unstable at high-temperature ranges. To solve this issue many techniques have developed to prepare $\mathrm{TiO}_{2}$ on the plastic material. Researchers used low temperature methods for this purpose such as ball lift-off method, electrodepositing, chemical sintering and ball milling. Hagfelt et al. introduced press method. Photoelectrode was deposited on a plastic material which was conductive by nature and press method was used for the preparation of photoanode $[21,22]$. The plastic substrate has low efficiency as compared to the glass substrate for DSSC. The major 
problem with the plastic substrate is that it has thermal instability at a temperature of $450-550{ }^{\circ} \mathrm{C}$ which is necessary for the sintering process of Titanium dioxide. [21-32]. Press method is considered better to produce a plastic substrate for DSSC electrode at low temperature and already $8.1 \%$ efficiency has been achieved by this method [33]. The flexible electrode is being made by another interesting method in which thin metal sheets were used for photoelectrode substrate and for the counter electrode conductive plastic sheet was used [34]. Here we used Lignocelluloses with $\mathrm{TiO}_{2}$ and zinc oxide which can add flexibility to different substrates.

\section{Sensitizer}

The dye has its great part in photoconversion efficiencies of DSSCs. As the working function of DSSC relies on the HOMO and LUMO energy levels of the sensitizer and rate of electron transfer to the semiconductor material on photoanode, metal-free organic dyes and metal organic dyes have been used. Mostly metal organic dyes are used due to its broad absorption range [19]. There are different types of dyes are being used to get more efficiencies. Rutheniumbased N945 dye got attention due to better results with $\mathrm{TiO}_{2}$ by achieving a high current density of $18.84 \mathrm{~mA} / \mathrm{cm}^{2}$ and efficiency of $10.82 \%$ [36-37]. Moreover, $11.4 \%$ efficiency has obtained via using Heterolytic polypyridyl Ruthenium sensitizer (C106) [38]. With iodine redox couple N719 dye shows $11.2 \%$ efficiency which is better than previous [39]. Natural dyes are also available extracted from different types of plants. The disadvantage of these dyes is that obtained efficiencies of DSSC are low as compared to the Silicon solar cells. The dye obtained from Betaine pigments shows the highest efficiency at $1.70 \%$ [40].

\section{Electrolyte}

Redox couple liquid electrolyte is used widely in DSSC. It produces more photocurrent efficiency. Classification of major components of the liquid electrolyte can be described as organic solvent, additive and redox couple. It contains less viscosity [41]. Liquid electrolyte can be replaced by the solid-state electrolyte in DSSC. Solid state hole transporting materials (HTMs) are p-type semiconductors. Organic and inorganic HTMs have been used in solid-state DSSCs. Less than 1\% efficiency was reported by first prepared solid-state electrolyte based DSSC [42]. Now with certain improvements, organic HTMs got 7.1\% efficiency [43]. Other options are also there like polyacrylonitrile-based composite gel is used as a gel electrolyte having an efficiency of $4.4 \%$ moreover thermoplastic gel electrolyte has a better efficiency of $7.22 \%$ [44].

\section{Conclusion}

Renewable energy is more reliable energy in the world, as it does not affect the environment. Of all renewable energy resources, solar energy is more significant due to vast supply on the earth from the sun. To convert light energy into electrical energy, solar cells are best options. Among other types of solar cells dye-sensitized solar cell (DSSC) is low cost, environmentally friendly and can be made flexible as well due to easy synthesized process. As in the modern era, people are getting more attention towards smart and flexible gadgets that should be renewable in working and unaffected for society.

\section{References}

1. Karmakar AS, Ruparelia JP (2011) A Critical Review on Dye-Sensitized Solar Cell. International Conf Curr Trends Technol, pp. 8-10.

2. Singh E, Kim KS, Yeom GY, Nalwa HS (2017) Two-dimensional transition metal dichalcogenide-based counter electrodes for dye-sensitized solar cells. RSC Adv 7(45): 28234-28290.

3. Gong, Liang J, Sumathy K (2012) Review on dye-sensitized solar cells (DSSCs): Fundamental concepts and novel materials. Renew Sustain Energy Rev 16(8): 5848-5860.

4. Oregan, Grätzel M (1991) A low-cost, high-efficiency solar cell based on dyesensitized colloidal $\mathrm{TiO}_{2}$ films. Nature 353(6346): 737.

5. Hagfeldt, Boschloo G, Sun L, Kloo L, Pettersson H et.al. (2010) Dyesensitized solar cells. Chem Rev 110(11): 6595-6663.

6. Chen Y, Wang M, Li JY, Pootrakulchote N, Alibabaei L (2009) ACS Nano 3: 3103-3109.

7. Nemoto J, Sakata M, Hoshi T, Ueno H, Kaneko M (2007) All-plastic dyesensitized solar cell using a polysaccharide film containing excess redox electrolyte solution. J Electroanal Chem 599(1): 23-30.

8. Yamaguchi T, Tobe N, Matsumoto D, Arakawa H(2007) Highly efficient plastic substrate dye-sensitized solar cells using a compression method for preparation of $\mathrm{TiO}_{2}$ photoelectrodes. Chem Commun 45: 4767-4769.

9. McEvoy AJ, Grätzel M (1994) Sensitisation in photochemistry and photovoltaics. Sol Energy Mater Sol Cells 32(3): 221-227.

10. Chen CY, Wang M, Li JY, Pootrakulchote N, Alibabaei L et.al. (2009) Highly efficient light-harvesting ruthenium sensitizer for thinfilm dyesensitized solar cells. ACS Nano 3(10): 3103-3109.

11. Yella A (2011) Porphyrin-sensitized solar cells with cobalt (II/III)-based redoxelectrolyte exceed 12 percent efficiency. 334(6056): 629-634.

12. Rakesh K, Pandikumar A, Jothivenkatachala K(2013) Dye-SensitizedSolar Cell: A Summary. Mater Sci Forum 771: 1-24.

13. Braunstein G, Muraviev A, Saxena H, There N, Richter V et.al. (2005) p type doping of zinc oxide by arsenic ion implantation. Appl Phys Lett 87(19): 192103.

14. Park JO, Lee JH, Kim JJ, Cho SH, Cho YK (2005) Crystallization of indium tin oxide thin films prepared by RF-magnetron sputtering without external heating. Thin Solid Films 474(1-2): 127-132.

15. Kim H (1999) Electrical optical and structural properties of indium-tinoxide thin films for organic light-emitting devices. J Appl Phys 86(11): 6451-6461.

16. Kawashima T, Ezure T, Okada K, Matsui H, Goto K et al. (2004) FTO/ITO double-layered transparent conductive oxide for dye-sensitized solar cells. J Photochem Photobiol A Chem 164(1-3): 199-202.

17. Zumeta I, Ayllon JA, Gonzalez B, Domenech X, Vigil E (2009) $\mathrm{TiO}_{2}$ films obtained by microwave-activated chemical-bath deposition used to improve $\mathrm{TiO}_{2}$ - conducting glass contact. Sol Energy Mater Sol Cells 93(10): 1728-1732.

18. Lindström H, Holmberg A, Magnusson E, Malmqvist L, Hagfeldt A (2001) A new method to make dye-sensitized nanocrystalline solar cells at room temperature. J Photochem Photobiol a Chem 145(1-2): 107-112.

19. Lindström H, Holmberg A, Magnusson E, Lindquist SE, Malmqvist L, et al. (2001) A new method for manufacturing nanostructured electrodes on plastic substrates. Nano Lett 1(2): 97-100.

20. Miyasaka T, Ikegami M, Kijitori Y (2007) Photovoltaic performance of plastic dye-sensitized electrodes prepared by low-temperature binderfree coating of mesoscopic titania. J Electrochem Soc 154(5): A455-A461.

21. Boschloo G, Lindström H, Magnusson E, Holmberg A, Hagfeldt A (2002) Optimization of dye-sensitized solar cells prepared by compression method. J Photochem Photobiol A Chem 148(1-3): 11-15. 
22. Dürr M, Schmid A, Obermaier M, Rossell S, Yasuda A, et al (2005) Low temperature fabrication of dye-sensitized solar cells by transfer of composite porous layers. Nat Mater 4(8): 607.

23. Zhang D, Yoshida T, Minoura H (2003) Low-temperature fabrication of efficient porous titania photoelectrodes by hydrothermal crystallization at the solid/gas interface. Adv Mater 15(10): 814-817.

24. Park N, Kim KM, Kang MG, Ryu KS, Chang SH, et al. (2005) Chemical sintering of nanoparticles: a methodology for low-temperature fabrication of dye- sensitized $\mathrm{TiO}_{2}$ films. Adv Mater 17(19): 2349-2353.

25. Miyasaka T, Kijitori Y (2004) Low-temperature fabrication of dyesensitized plastic electrodes by electrophoretic preparation of mesoporous $\mathrm{TiO}_{2}$ layers. J Electrochem Soc 151(11): A1767-A1773

26. Uchida S, Tomita M, Takizawa H, Kawaraya M (2004) Flexible dyesensitized solar cells by $28 \mathrm{GHz}$ microwave irradiation. J Photochem Photobiol A Chem 164(1-3): 93-96.

27. Haque S A (2003) Flexible dye-sensitized nanocrystalline semiconductor solar cells. Chem Commun 24: 3008-3009.

28. Kijitori Y, Ikegami M, Miyasaka T (2007) Highly efficient plastic dyesensitized photoelectrodes prepared by low-temperature binder-free coating of mesoscopic titania pastes. Chem Lett 36 9(1): 190-191.

29. Yamaguchi T, Tobe N, Matsumoto D, Nagai T, Arakawa H (2010) Highly efficient plastic-substrate dye-sensitized solar cells with validated conversion efficiency of 7.6\%. Sol Energy Mater Sol Cells 94(5): 812-816.

30. Ito S (2006) High-efficiency (7.2\%) flexible dye-sensitized solar cells with Timetal substrate for nanocrystalline- $\mathrm{TiO}_{2}$ photoanode. Chem Commun 38: 4004-4006.

31. Calisir MD, Stojanovska E, Kilic A (2018) Polymer nanocomposites for dyesensitized solar cells. in Polymer-based Nanocomposites for Energy and Environmental Applications Elsevier, pp: 361-396.

32. Nazeeruddin MK (2007) A high molar extinction coefficient charge transfer sensitizer and its application in a dye-sensitized solar cell. J Photochem Photobiol a Chem 185(2-3): 331-337.
33. Yu Q, Liu S, Zhang M, Cai N, Wang Y, et al. (2009) An extremely high molar extinction coefficient ruthenium sensitizer in dye-sensitized solar cells: the effects of $\pi$-conjugation extension. J Phys Chem C113 (32): 1455914566.

34. Cao Y (2009) Dye-sensitized solar cells with a high absorptivity ruthenium sensitizer featuring a 2-(hexylthio) thiophene conjugated bipyridine. Phys Chem C 113(15): 6290-6297.

35. Nazeeruddin MK (2005) Combined experimental and DFT TDDFT computational study of photoelectrochemical cell ruthenium sensitizers. J Am Chem Soc 127(48): 16835-16847.

36. Calogero G, Gaetano Di Marco, Silvia Cazzanti,Stefano Caramori, Roberto Argazzi, et al. (2010) Efficient dye-sensitized solar cells using red turnip and purple wild Sicilian prickly pear fruits. Int J Mol Sci 11(1): 254-267.

37. Srinivasan S (1987) Proceedings of the Symposium on electrode materials and processes for energy conversion and storage.

38. Park G Schlichthörl, J Van de Lagemaat, HM, Cheong A, Mascarenhas, et al. (1999) Dye-sensitized $\mathrm{TiO}_{2}$ solar cells: structural and photoelectrochemical characterization of nanocrystalline electrodes formed from the hydrolysis of TiCl4. J Phys Chem B 103(17): 3308-3314.

39. HY Byun, Vittal (2004) Beneficial role of cetyltrimethylammonium bromide in the enhancement of photovoltaic properties of dye-sensitized rutile $\mathrm{TiO}_{2}$ solar cells. Langmuir 20(16): 6853- 6857.

40. Fujishima A, Honda k (1972) Electrochemical photolysis of water ata semiconductor electrode. Nature 238(5358): 37.

41. https://www.ncbi.nlm.nih.gov/pubmed/20414239

42. U Bach (2000) Solid-state dye sensitized mesoporous $\mathrm{TiO}_{2}$ solar cells.

43. Burschka (2011) Tris (2-(1 H-pyrazol-1-yl) pyridine) cobalt (III) as a p-type dopant for organic semiconductors and its application in highly efficient solid-state dye-sensitized solar cells. J Am Chem Soc 133(45): 18042-18045.

44. JH Wu (2007) A thermoplastic gel electrolyte for stable quasi-solid-state dye- sensitized solar cells. Adv Funct Mater 17(15): 2645-2652.

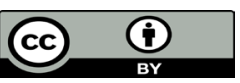

This work is licensed under Creative Commons Attribution 4.0 License

To Submit Your Article Click Here: Submit Article

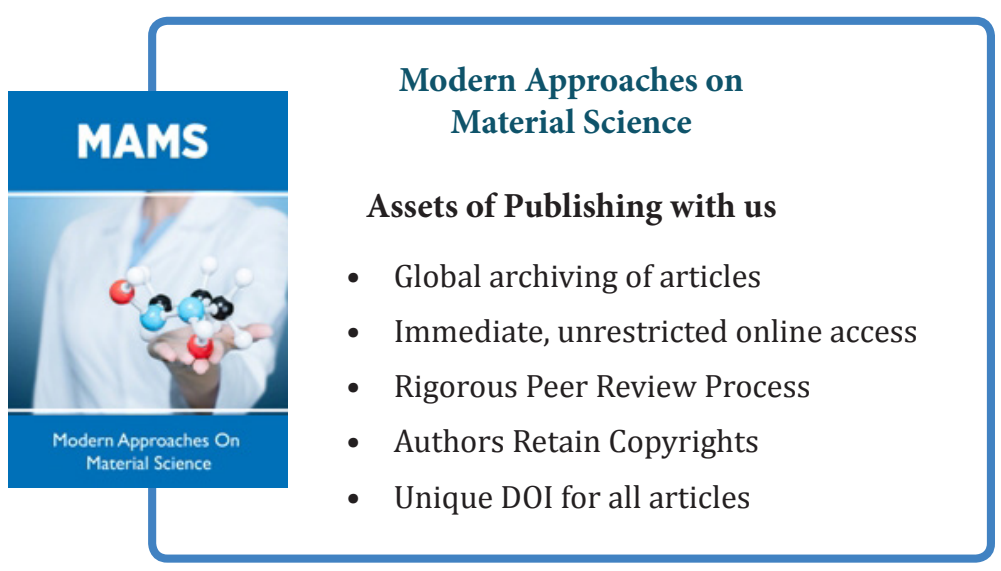

